\title{
Cellular assessment of muscle in COPD: case studies of two males
}

This article was published in the following Dove Press journal:

International Journal of General Medicine

6 November 2009

Number of times this article has been viewed

\author{
Howard J Green' \\ Eric Bombardier' \\ Margaret E Burnett ${ }^{\prime}$ \\ Christine L D'Arsigny ${ }^{2}$ \\ Sobia Iqbal' \\ Katherine A Webb ${ }^{2}$ \\ Jing Ouyang' \\ Denis E O’Donnell ${ }^{2}$ \\ 'Department of Kinesiology, \\ University of Waterloo, Waterloo, \\ ON, Canada; ${ }^{2}$ Division of Respiratory \\ and Critical Care Medicine, \\ Department of Medicine, Queen's \\ University, Kingston, ON, Canada
}

Correspondence: Howard J Green Department of Kinesiology, University of Waterloo, Waterloo, ON, Canada, N2L3GI

Tel +I 5198884567 Ext 33454

Fax +I 5198850470

Email green@healthy.uwaterloo.ca
Abstract: The objective of this paper is to provide an overview of the recent developments in muscle physiology and biochemistry in general, and with respect to chronic obstructive pulmonary disease (COPD) specifically. As a way of illustration, we have presented data on the remodeling that occurs in vastus lateralis in two patients with COPD (COPD \#1, forced expiratory volume in one second/forced vital capacity $\left[\mathrm{FEV}_{1} / \mathrm{FVC}\right]=63 \%$; $\mathrm{COPD} \# 2, \mathrm{FEV}_{1} /$ $\mathrm{FVC}=41 \%$ ) exhibiting differences in muscle wasting as compared to healthy controls (CON; $\left.\mathrm{FEV}_{1} / \mathrm{FVC}=111 \pm 2.2 \%, \mathrm{n}=4\right)$. Type I fibers percentages were lower in both COPD \#1 (16.7) and COPD \#2 (24.9) compared to CON (57.3 \pm 5.2$)$. Cross sectional area of the type I fibers of the patients ranged between $65 \%-68 \%$ of $\mathrm{CON}$ and for the type II subtypes (IIA, IIAX, IIX) between $74 \%$ and $89 \%$ (COPD \#1) and 17\%-32\% (COPD \#2). A lower number of capillary contacts were observed for all fiber types in COPD \#1 but not COPD \#2. Lower concentrations of adenosine triphosphate (ATP) (24\%-26\%) and phosphocreatine (18\%-20\%), but not lactate occurred in COPD. In contrast to COPD \#1, who displayed normal glucose transporter content, GLUT1 and GLUT4 were only $71 \%$ and 54\%, respectively of CON in COPD \#2. Lower monocarboxylate contents were found for MCT1 in both COPD \#1 (63\%) and COPD \#2 (41\%) and for MCT4 (78\%) in COPD \#1. Maximal oxidative enzyme activities $\left(\mathrm{V}_{\max }\right)$ for COPD \#2 ranged between $37 \%$ (succinic dehydrogenase) and 70\% (cytochrome $\mathrm{C}$ oxidase) of CON. For the cytosolic enzymes, $\mathrm{V}_{\max }$ ranged between $89 \%$ (hexokinase) to $31 \%$ (pyruvate kinase) of CON. Depressions were also observed in $\mathrm{V}_{\max }$ of the $\mathrm{Na}^{+}-\mathrm{K}^{+}$-ATPase for COPD \#1 (66\% of CON) but not COPD \#2 ( $92 \%$ of $\mathrm{CON}$ ) while $\mathrm{V}_{\max }$ of the $\mathrm{Ca}^{2+}$-ATPase was near normal in COPD \#1 (84\% CON). It is concluded that disturbances can occur in muscle to a wide range of excitation, contraction and metabolic processes in COPD.

Keywords: vastus lateralis, fiber types, area, capillarization, metabolism, enzymatic pathways, excitation-contraction processes, glucose and monocarboxylate transporters

\section{Introduction}

It has become clear that the clinical management of patients with chronic obstructive pulmonary disease (COPD) in addition to treating the symptoms occurring as a direct result of the disease itself must also address some of the side effects of the disease. One side effect is the profound disability in exercise tolerance that occurs. It is now recognized that muscle dysfunction itself can be represent at least part of the etiology of the failure of COPD patients to perform many daily tasks of living. ${ }^{1,2}$

Efficient and effective therapeutic rehabilitation strategies depend on understanding the mechanisms underlying the cause of the inability of the muscle to generate desired force responses. With this knowledge, dedicated protocols can be designed 
to improve specific outcomes, assuming that the disease does not prevent the appropriate cellular remodeling that is required. However, in general, clinical practice has not evolved to a state where specific functional deficits are identified and related to specific cellular abnormalities. There are several reasons for this, not the least of which is the incomplete knowledge of the recent advances that have been made in muscle physiology and biochemistry. Much progress has been made in the development of analytical protocols for the characterization of specific proteins and processes in the muscle cell and their role in mechanical behavior. Many of these properties can be assessed on relatively small amounts of tissue easily obtained by muscle biopsy. These techniques have been employed to determine the cellular abnormalities in a variety of disease states including COPD. However, in the case of COPD, relatively few studies have been published and as a result there is an inadequate understanding of the specific cellular alterations that occur in patients. ${ }^{2-4}$ Although it is recognized that in COPD the ability to generate an expected peak force and/or to engage to repetitive activity are compromised, ${ }^{2}$ studies have generally not measured the appropriate contractile properties responsible for these abnormalities.

In this review, we have several objectives. One major objective is to provide an overview, consistent with current knowledge, of the cellular processes regulating contractile behavior and the role of specific proteins and protein isoforms in mediating the functional properties of the processes. In addition, we summarize the literature on muscle and COPD, identifying areas where there is little or no published data. Finally, we provide information on specific analytical protocols that can be employed to provide a comprehensive assessment of muscle in COPD. To enhance clinical interest, we have supplemented the review with the results of two male COPD patients, differing in amount of lean body mass to illustrate via the detailed characterization performed, the differences in both the type and magnitude of the muscle abnormalities present.

It is well established that the loss of lean body mass (cachexia) frequently accompanying COPD compromises muscle force-generating potential as a result of fiber atrophy..$^{2-4}$ Although the loss of muscle mass is undoubtedly important in the functional deficit that occurs, changes within the muscle fiber also appear important. In general, characterization of muscle in COPD has generally failed to address this aspect. In the following sections, a brief overview is provided of the relevant components involved with insight into the measurement of specific properties.
Characterization of the potential of the muscle cell to perform contractile activity depends on an analysis of both of the excitation and contraction processes ( $\mathrm{E}-\mathrm{C}$ processes) in addition to the organization of the metabolic pathways that generate the energy for the $\mathrm{E}-\mathrm{C}$ processes to perform their functions. Key elements in the $\mathrm{E}-\mathrm{C}$ processes amenable to measurement in humans have typically involved the processes and proteins involved in cation cycling, namely the transport of $\mathrm{Na}^{+}$and $\mathrm{K}^{+}$across the sarcolemma and t-tubule and the uptake and release of $\mathrm{Ca}^{2+}$ by the sarcoplasmic reticulum (SR). The $\mathrm{Na}^{+}-\mathrm{K}^{+}$-ATPase and the SR $\mathrm{Ca}^{2+}$-ATPase are the critical enzymes involved in the active transport of these cations and consequently measurement of their properties is essential. Typically, in muscle homogenates, the measurements include the catalytic activities of the enzymes involved, the protein and the isoform abundance. In the case of the SR, $\mathrm{Ca}^{2+}$-release and $\mathrm{Ca}^{2+}$-uptake can also be assessed.

Our studies appear to be among the first to examine selected properties in the vastus lateralis (VL) E-C processes in COPD. We have found that the maximal catalytic activities $\left(\mathrm{V}_{\max }\right)$ of both enzymes were depressed which occurred in association with alterations of the subunit isoforms. ${ }^{5,6}$

Although measurements of the catalytic activity of the myosin ATPase have not been reported in COPD, measurements of the fiber types and subtypes have been published. It is well established that in COPD, the muscle contains a higher percentage of type II and a lower percentage of type I fibers, ${ }^{7}$ the magnitude of the change in fiber types dependent on disease severity. ${ }^{8,9}$ The determination of fiber types is based on the myosin isoforms and specifically the heavy chain isoforms which contain the ATPase. ${ }^{10}$ Interestingly, a well established effect of COPD is a reduction of muscle mass. ${ }^{11}$ Given that the contractile proteins represent the majority of muscle protein, changes in one or more of the contractile proteins would be expected in COPD.

The primary function of the metabolic pathways is to supply the adenosine triphosphate (ATP) required by the ATPases to perform their unique functions. Consequently, it is possible that contractile failure may occur secondary to disturbances in energy homeostasis, mediated by deficiencies in metabolic pathway potential. The metabolic pathways and segments include high energy phosphate transfer, glycolysis, and oxidative phosphorylation.

The success of the metabolic pathways in responding to the demands for ATP, both at rest and during increased contractile activity, is based on the ability to protect phosphorylation potential $^{12}$ which is determined primarily by the concentrations of ATP and PCr. Characterization of metabolic 
pathway potentials in muscle in COPD patients represent the most popular area of publication to date.

At the level of the organization of the metabolic pathways, it is commonly assumed that the potential for oxidative phosphorylation has been compromised in COPD. ${ }^{2,3}$ However, at least in the locomotor muscles, this assumption is based on the measurement of relatively few enzymes with reductions in the maximal activity of citrate synthase, an enzyme of the CAC, cited as primary evidence. ${ }^{13}$ Similarly, of the few studies which have concluded that the glycolytic potential is not affected in COPD, the same problem applies, namely the measurement of relatively few enzymes. ${ }^{14-16}$ These assumptions are further compounded by the fact that not all studies in this area report similar effects of COPD. ${ }^{16,17}$ In recent work from our group, in which we have measured a broad range of enzymes, we have found that both the potential for $\beta$-oxidation and oxidative phosphorylation (based on cytochrome oxidase) were depressed while the potential for glucose phosphorylation was increased. ${ }^{18}$

Since the flux rate in the metabolic pathways can also be limited by the availability of substrates such as $\mathrm{CHO}$ and accumulation of metabolic byproducts, it is important that measurement be made of the processes which control these properties. Glucose transport into the muscle, as an example, is facilitated by a family of glucose transporters (GLUT) of which GLUT1 and GLUT4 are primarily expressed in skeletal muscle. ${ }^{19}$ Similarly, the diffusion of the byproducts $\mathrm{H}^{+}$and lactate is facilitated by monocarboxylate transporters (MCT) in which MCT1 and MCT4 predominate in skeletal muscle. ${ }^{20}$ In what appears to be the first study measuring these properties in skeletal muscle, we have found that the principal transporters, namely GLUT4 and MCT4, were depressed in the vastus lateralis of COPD patients. ${ }^{21}$

Histochemistry provides an opportunity to determine if the changes observed in muscle of COPD patients are specific to different fiber types. Curiously, relatively few studies have addressed this area and those that used histochemistry measured relatively few properties. An association between properties of the $\mathrm{E}-\mathrm{C}$-coupling processes and the potential of the metabolic pathways and segments in skeletal muscle of COPD patients would be expected. It is well established that the expression of these properties is correlated in the various fiber types and subtypes. ${ }^{22}$ The most consistent finding published to date is that in the VL, COPD is accompanied by a decrease in type I and an increase in type II fiber percentages. ${ }^{8}$ If the increase in type II fibers in COPD represents a simple transformation from type I fibers as proposed, ${ }^{2,3}$ it would be expected that the $\mathrm{E}-\mathrm{C}$-coupling processes would be altered accordingly, resulting in a more emphasized SR as an example. Similarly, the potential high-energy phosphate transfer and glycolysis should be increased and the oxidative potential decreased. Alternatively, if COPD acts directly on the E-C-coupling processes and the metabolic pathways, as suspected, possibly as a result of the accumulation of reactive oxygen species (ROS), ${ }^{23}$ reductions may occur regardless of the fiber-type shifts. Moreover; since cachexia is known to be prevalent in COPD, resulting in a loss of lean body mass, ${ }^{24}$ it is possible that the areas of the different fiber types may be affected.

Histochemistry also provides the opportunity to assess the perfusion potential of the different fiber types. Given that the functional integrity of the metabolic pathways is also dependent on the supply of substrates such as $\mathrm{O}_{2}$ from the circulation, measurements of capillary density of the muscle fibers in conjunction with fiber areas is a desirable addition. ${ }^{25}$

In this review, for purposes of illustration, we have provided a comprehensive assessment of both the E-C-coupling processes and the metabolic pathways in COPD. We have concentrated on the muscle characteristics of two male patients differing in COPD severity and in cachexia severity on whom we had sufficient tissue from the VL to perform an extensive array of measurements using techniques modified for the measurement of properties on small amounts of tissue. Our guiding hypothesis was that in the COPD patients compared to healthy controls, a higher percentage of type II and a lower percentage of type I fibers would be observed in conjunction with a lower cross sectional area and lower capillarization of the fiber types. These differences would be accompanied by a lower oxidative potential and a higher potential for high-energy phosphate transfer and glycolysis. In addition, it is proposed that the catalytic potential of the $\mathrm{Ca}^{2+}$-ATPase as well a the capacity for $\mathrm{Ca}^{2+}$-uptake and $\mathrm{Ca}^{2+}$ release would be higher in COPD. In contrast, the capacity for $\mathrm{Na}^{+}-\mathrm{K}^{+}$-ATPase activity would be lower in COPD compared to controls.

This work was part of a much larger project investigating skeletal muscle in COPD in which we have published a number of papers dealing with metabolic organization, ${ }^{18}$ the sarcoplasmic reticulum, ${ }^{5}$ the $\mathrm{Na}^{+}-\mathrm{K}^{+}$-ATPase,${ }^{6}$ energetic and transporters status ${ }^{21}$ and muscle fiber type characteristics. ${ }^{26}$

\section{Methods}

\section{Participants}

In this report, we have selected two male patients with advanced COPD and compared the characteristics of the 
vastus lateralis muscle with four healthy male control (CON) subjects. The two patients with COPD recruited from a list of patients who had participated in previous research studies at the Respiratoty Investigation Unit at Queen's University (Canada). Healthy volunteers were recruited from the local community primarily by newspaper advertisements. Informed consent was obtained from all participants and ethics approval was obtained from the University and Hospital Health Sciences Human Research Ethics Board.

As can be observed in Table 1, the patients were both aged 66 years and weighed between 63.9 (COPD \#1) and $44.6 \mathrm{~kg}$ (COPD \#2). Comparable values for CON were age, $64.8 \pm 3.6$ years and $80.9 \pm 8.3 \mathrm{~kg}$, respectively. The body mass index (BMI; kg/m²) was 23.8 and 15.3 for COPD \#1 and COPD \#2 which compared to $25.7 \pm 2.1$ for CON. The forced expiratory volume in one second/forced vital capacity $\left(\mathrm{FEV}_{1} / \mathrm{FVC}\right.$; \%) ranged between 62.7 and 40.7 for the COPD patients compared to $111 \pm 2.2$ for CON. As expected, arterial $\mathrm{O}_{2}$ saturation $\left(\mathrm{SaO}_{2}, \%\right)$, diffusing capacity $\left(\mathrm{D}_{\mathrm{LCO}}, \%\right.$ pred $)$ was depressed in both COPD \#1 and COPD \#2 compared to $\mathrm{CON}$.

In terms of medication, COPD \#1 was on Combivent (short-acting $\beta_{2}$-agonist + short-acting anticholinergic), Advair (long-acting $\beta_{2}$-agonist + inhaled corticosteroid) and Spiriva (long-acting anticholinergic). For COPD \#2,

Table I Anthropometric, pulmonary function and exercise characteristics of control and two patients with chronic obstructive pulmonary disease

\begin{tabular}{llll}
\hline & Con & COPD \#I & COPD \#2 \\
\hline Age $(\mathrm{yr})$ & $64.8 \pm 3.6$ & 66 & 66 \\
Weight $(\mathrm{kg})$ & $80.9 \pm 8.3$ & 63.9 & 44.6 \\
Height $(\mathrm{cm})$ & $177 \pm \mathrm{I} .5$ & 164 & 171 \\
Body mass index $\left(\mathrm{kg} / \mathrm{m}^{2}\right)$ & $25.7 \pm 2.1$ & 23.8 & 15.3 \\
$\mathrm{FEV}_{1}(\mathrm{~L})$ & $3.36 \pm 9.2$ & 0.49 & 0.54 \\
$\mathrm{FEV}_{1}(\%$ predicted $)$ & $110 \pm 2.2$ & 20 & 19 \\
$\mathrm{FEV}_{1} / \mathrm{FVC}(\%)$ & $111 \pm 2.2$ & 62.7 & 40.7 \\
$\mathrm{D}_{\text {Lco }}(\%$ predicted $)$ & $124 \pm 17$ & 53.4 & 28.8 \\
$\mathrm{PaO}_{2}(\mathrm{mmHg})$ & $82.7 \pm 1.2$ & $\mathrm{NA}$ & 45.1 \\
$\mathrm{PaCo}_{2}(\mathrm{mmHg})$ & $43.7 \pm 2.0$ & $\mathrm{NA}$ & 46.6 \\
$\mathrm{SaO}_{2}(\%)$ & $95.6 \pm 0.26$ & 92 & 82.2 \\
$\mathrm{VO}_{2 \text { peak }}\left(\mathrm{ml} \cdot \mathrm{kg}{ }^{-1} \mathrm{~min}\right)$ & $30.5 \pm 3.1$ & 7.3 & 5.7 \\
$\mathrm{Maximal}$ torque $(\mathrm{Nm})$ & $152 \pm 16$ & 39.8 & 19.2
\end{tabular}

Notes: Values are $\bar{x} \pm S E$. For Con, $\mathrm{n}=4$.

Abbreviations: Con, control; COPD \#I and COPD \#2, two chronic obstructive pulmonary disease patients; $\mathrm{FEV}_{1}$, forced expiratory volume in one second; FVC, forced vital capacity; $\mathrm{D}_{\mathrm{Lco}}$, diffusing capacity of the lung for carbon monoxide; $\mathrm{PaO}_{2}$, arterial oxygen tension; $\mathrm{PaCo}_{2}$, arterial carbon dioxide tension; $\mathrm{SaO}_{2}$, arterial oxygen saturation; $\mathrm{VO}_{2 \text { peak }}$, peak oxygen consumption during progressive exercise; maximal torque, maximal knee extention torque generated at $30^{\circ} \mathrm{s}$; NA, not available. the medications included Ventolin (short-acting $\beta$-agonist), Flovent (inhaled corticosteroid) and Atrovent. None of the CON subjects were on any of these medications. COPD \#1 had smoked for 47 pack-years, while COPD \#2 had smoked for 45 pack-years. Both COPD patients were on supplemental $\mathrm{O}_{2}$, either continuously (COPD \#2) or continuously during the day (COPD \#1). Information describing the inclusion and exclusion criteria for both the COPD and CON volunteers have been reported previously. ${ }^{5,18}$

Peak oxygen consumption $\left(\dot{V} O_{2 \text { peak }}\right)$, measured during cycle ergometry, was $7.3,5.7$, and $30.5 \pm 3.1 \mathrm{ml} \cdot \mathrm{kg}^{-1} \cdot \mathrm{min}$ for COPD \#1, COPD \#2 and CON, respectively (Table 1). For the COPD patients, these values were only $33 \%$ (COPD \#1) and 20\% (COPD \#2) of predicted. Dynamic knee extension torque measured by computerized isokinetic dynameter (Cybex International, Medway, MA, USA) was also severely depressed in COPD with values of 39.8 and $19.2 \mathrm{Nm}$ measured for COPD \#1 and COPD \#2, respectively. For $\mathrm{CON}$, the maximal torque was $152 \pm 16 \mathrm{Nm}$.

Additional details for test protocols appear in earlier papers. ${ }^{5,6,18,21}$

\section{Tissue sampling}

Tissue was obtained from the vastus lateralis on the dominant side using the needle biopsy technique. ${ }^{27}$ With this technique, the sampling site is identified (mid thigh), a small incision made after local freezing (lidocaine), and the tissue harvested using two to three separate biopsies. The biopsies were performed rapidly in succession, using fresh sterilized needles, by trained personnel. The needle containing the tissue from the first biopsy was rapidly plunged into liquid $\mathrm{N}_{2}$ and subsequently removed without thawing and stored at $-80^{\circ} \mathrm{C}$ until analyses. This tissue was used for the measurement of the substrate, glycogen and the labile high energy phosphagen compounds and related metabolites and the glycolytic intermediates. The tissue obtained from the additional biopsies was extracted from the needle, a section isolated and a homogenate prepared before freezing and storage at $-80{ }^{\circ} \mathrm{C}$. The remaining tissue was frozen in liquid $\mathrm{N}_{2}$ and stored at the same low temperature and a section prepared for histochemistry prior to freezing and storage.

\section{Analytical protocols}

The extensive array of properties was measured on different days during separate analytical sessions. For the measurement of a given property, all samples, both CON and COPD, were assessed during the same analytical session. 
The measurements performed included the labile metabolic compounds, a range of enzymes, GLUT and MCT isoforms, SR-related properties and the properties of the $\mathrm{Na}^{+}-\mathrm{K}^{+}$-ATPase (Table 2). These measurements were also complemented by the assessment of fiber-type related properties using histochemistry. Since all analytical techniques covering the properties assessed have been reported in detail in previous studies from this project, descriptions are kept to a minimum.

\section{Histochemistry}

We have used histochemistry to assess the distribution of the various fiber types and subtypes and to determine the crosssectional areas (CSA) and the number of capillaries in contact (CC) with fiber classification. These measurements were also complemented by determinations of both the maximal activity of succinate dehydrogenase (SDH) and the $\mathrm{Ca}^{2+}$-ATPase in fiber-specific types using microphotometric techniques. In brief, the histochemical procedures involved making serial slices of the muscle sample mounted in cross section in a cryostat $\left(-20^{\circ} \mathrm{C}\right)$ and measuring the specific properties in successive sections. The first property assessed was the fiber type distribution using the procedures of Staron and colleagues, ${ }^{28}$ which permitted identifying the distribution of type I, IC, IIC, IIA, IIAX, and IIX. Identification was based on the $\mathrm{pH}$ lability of the myofibrillar ATPase reaction, ${ }^{28,29}$ which is determined by the heavy chain isoform (HC) content, of which the ATPase is part of. For CON, an average of $216 \pm 29$ fibers were and for COPD \#1 and COPD \#2, the numbers were 150 and 213, respectively. Capillary contacts (CC) per fiber was permitted by using a lectin (ulex europaeus I) technique which allowed visualization of the capillaries. ${ }^{30}$ The activity of SDH was based on the determinations of the optical density (OD units) using the nitro blue tetrazolium as the reaction indicator. ${ }^{31}$ Similarly, the SR $\mathrm{Ca}^{2+}$-ATPase activity was measured using similar microphotometric techniques according to the procedures of van Der Laarse ${ }^{32}$ as modified in our laboratory. ${ }^{33}$ The OD was obtained using an image analysis system (Image-Pro; Media Cybernetics, Silver Spring, MD, USA). Where possible 25 fibers of each type were assessed for these properties.

The fibers stained for SDH were also used to obtain the CSA of a similar number of fibers of each type, using a video monitor digitizing tablet. The CSA measurements in combination with the $\mathrm{CC}$ allowed calculation of the ratio of $\mathrm{CC}$ to $\operatorname{CSA}\left(\mu \mathrm{m}^{2} \cdot 10^{-3}\right)$.

By using serial sections we were able to select a subgroup of specific fibers of each type and to measure all the properties in this sample of fibers.

\section{Enzyme activities}

To characterize the enzymatic pathways and segments we have measured the maximal activities $\left(\mathrm{V}_{\text {max }}\right)$ of a wide range of enzymes which consisted of five from the mitochondria and five from the cytosol. The mitochondrial enzymes selected included three from the citric acid cycle (CAC), namely citrate synthase (CS), SDH, and malate dehydrogenase (MDH), one to represent $\beta$-oxidation, 3-hydroxyacyl-CoA dehydrogenase (HADH) and a complex of the electron transport system (ETC), cytochrome C oxidase (COX). The cytosolic enzymes were selected to represent glucose oxidation, hexokinase (HEX), glycogenolysis, phosphorylase (PHOSPH), glycolysis, phosphfructokinase (PFK), pyruvate kinase (PK), lactate dehydrogenase (LDH), high-energy phosphate transfer, and creatine phosphokinase (CPK). Multiple enzymes were selected from specific pathways to determine if they all responded in the same way with COPD. It has been assumed in studies investigating muscle in COPD that since the enzymes in a given pathway are in constant proportion to each other in the healthy subject, ${ }^{34}$ that a single enzyme can be used to represent a pathway. This may not be so in unhealthy subjects.

With the exception of COX, all enzymes were measured fluorometrically at $24-25{ }^{\circ} \mathrm{C}$ in homogenates according to previously published procedures..$^{35,36}$ With the exception of SDH and PFK, which were measured on fresh homogenates, prepared just prior to assay, all other enzymes were measured on homogenates that had been frozen after preparation. A spectrophotometric assay $\left(30^{\circ} \mathrm{C}\right)$ was used to measure $\mathrm{COX}$ which was based on the disappearance of reduced cytochrome $\mathrm{C}$ aborbance.

Enzyme activities were expressed per unit protein which was assessed by the use of the Lowry method as modified by Schacterle and Pollock. ${ }^{37}$ Samples from both CON and COPD for a given enzyme were measured in duplicate and during the same analytical session.

\section{Metabolism}

To evaluate the metabolic status of the muscle, the concentrations of the adenine nucleotides (ATP, ADP, and AMP) were measured by high-performance liquid chromatography (HPLC) as described previously, ${ }^{38}$ and the total adenine nucleotide pool (TAN) was calculated. Measurements of inosine monophosphate (IMP) was also measured with HPLC techniques. These properties were complemented by fluorometric-based measurements of glycogen, the glycolytic metabolites, pyruvate (Pyr) and lactate (Lac) and the high-energy compound, creatine phosphate $(\mathrm{PCr})$ and its metabolite, creatine $(\mathrm{Cr})$. The measurements of $\mathrm{PCr}$ and 
Table 2 Summary of muscle characteristics studied in two patients with chronic obstructive pulmonary disease, techniques employed and properties assessed

\begin{tabular}{|c|c|c|c|c|}
\hline \multirow[t]{2}{*}{ Characteristic } & \multicolumn{2}{|l|}{ Patients } & \multirow[t]{2}{*}{ Technique } & \multirow[t]{2}{*}{ Properties } \\
\hline & COPD \#I & COPD \#2 & & \\
\hline \multicolumn{5}{|l|}{ Fiber types } \\
\hline Distribution & $*$ & $*$ & Myofibrillar ATPase 28,29 & Fiber Types (\%) \\
\hline Size & $*$ & $*$ & Digitizing tablet ${ }^{53}$ & Cross sectional area $\left(\mu \mathrm{m}^{2}\right)$ \\
\hline Capillarization & $*$ & $*$ & Lectin technique ${ }^{30}$ & Number of capillaries (CC) \\
\hline Oxidative potential & $*$ & $*$ & Microphotometry ${ }^{31}$ & SDH activity $\left(\mathrm{V}_{\max }\right)$ \\
\hline Cation transport & $*$ & $*$ & Microphotometry $y^{32,33}$ & $\mathrm{Ca}^{2+}$-ATPase activity $\left(\mathrm{V}_{\max }\right)$ \\
\hline \multicolumn{5}{|c|}{ Metabolic pathways $\left(\mathbf{V}_{\max }\right)$} \\
\hline $\mathrm{CS}, \mathrm{SDH}, \mathrm{MDH}$ & & $*$ & Fluorometric $\mathrm{c}^{35,36}$ & Citric acid cycle \\
\hline $\operatorname{cox}$ & & $*$ & Spectrophotometric ${ }^{18}$ & Electron transport system \\
\hline $\mathrm{HADH}$ & & $*$ & Fluorometric $^{35,36}$ & Fat oxidation \\
\hline HEX & & $*$ & Fluorometric $\mathrm{c}^{35,36}$ & Glucose oxidation \\
\hline $\mathrm{PHOSPH}$ & & $*$ & Fluorometric 35,36 & Glycogenolysis \\
\hline PFK, PK, LDH & & $*$ & Fluorometric 35,36 & Glycolysis \\
\hline CPK & & $*$ & Fluorometric $^{35,36}$ & $\begin{array}{l}\text { High-energy phosphate } \\
\text { transfer }\end{array}$ \\
\hline \multicolumn{5}{|l|}{$\begin{array}{l}\text { Metabolic status } \\
\text { (Concentration) }\end{array}$} \\
\hline ATP, ADP, AMP, IMP, TAN & $*$ & $*$ & HPLC 38 & Energy charge \\
\hline $\mathrm{PCr}, \mathrm{Cr}, \mathrm{TCr}$ & $*$ & $*$ & Fluorometry ${ }^{21}$ & Energy charge \\
\hline Pyruvate, lactate & $*$ & $*$ & Fluorometry ${ }^{21}$ & Glycolytic metabolites \\
\hline Glycogen & $*$ & $*$ & Fluorometry ${ }^{21}$ & Carbohydrate substrate \\
\hline \multicolumn{5}{|l|}{ Transporters (Content) } \\
\hline GLUTI, GLUT4 & $*$ & $*$ & Electrophoresis/Western blotting ${ }^{39}$ & Glucose transport \\
\hline MCTI, MCT4 & $*$ & $*$ & Electrophoresis/Western blotting ${ }^{39}$ & Lactate transport \\
\hline \multicolumn{5}{|l|}{ Cation transport } \\
\hline \multicolumn{5}{|l|}{$\mathrm{Na}^{+}-\mathrm{K}^{+}$-ATPase } \\
\hline $\mathrm{V}_{\max }$ & $*$ & $*$ & Spectrophotometric (3-0-MFPase) ${ }^{40,41}$ & Maximal activity \\
\hline Content & $*$ & $*$ & Scintillation $\left({ }^{3} \mathrm{H} \text {-Ouabain binding }\right)^{42}$ & Enzyme content \\
\hline \multicolumn{5}{|l|}{$\mathrm{Ca}^{2+}$-ATPase (SR) } \\
\hline $\mathrm{V}_{\max }, \mathrm{Ca}_{50}, \mathrm{\eta}_{\mathrm{H}}$ & $*$ & & Spectrophotometric ${ }^{44,45}$ & $\begin{array}{l}\text { Maximal activity; } \\
\mathrm{Ca}^{2+}-\text { sensitivity }\end{array}$ \\
\hline $\mathrm{Ca}^{2+}$-uptake & $*$ & & Spectrophotometric ${ }^{44,45}$ & $\mathrm{Ca}^{2+}$-uptake \\
\hline $\mathrm{Ca}^{2+}$-release & $*$ & & Spectrophotometric ${ }^{44,45}$ & $\mathrm{Ca}^{2+}$-release \\
\hline
\end{tabular}

Notes: The characteristics assessed included both the processes involved in the production of energy and the utilization of energy by the muscle cell. Metabolic status is a measure of the energetic state of the cell as assessed by the high-energy phosphate compounds. Metabolic pathway potential is based on the maximal activity $\left(V_{\text {max }}\right)$ of representative enzymes. For the transporter potential, the content of two isoforms of glucose and lactate were measured. For cation transport, the maximal activity $\left(\mathrm{V}_{\max }\right)$ of both the enzymes involved in sarcolemma and t-tubule transport of $\mathrm{Na}^{+} / \mathrm{K}^{+}$was measured $\left(\mathrm{Na}^{+}-\mathrm{K}^{+}\right.$-ATPase) as well as the sarcoplasmic reticulum (SR) Ca ${ }^{2+}$-uptake (Ca ${ }^{2+}$-ATPase). The SR Ca ${ }^{2+}$-ATPase was also supplemented by measures of $\mathrm{Ca}^{2+}$-release and $\mathrm{Ca}^{2+}$-uptake. Selected fiber type characteristics were assessed by histochemistry. See Methods for further details.

Abbreviations: $\mathrm{CS}$, citrate synthase; $\mathrm{SDH}$, succinic dehydrogenase; $\mathrm{MDH}$, malate dehydrogenase; $\mathrm{COX}$, cytochrome $\mathrm{c}$ oxidase; $\mathrm{HADH}-3$, hydroxyacyl-CoA dehydrogenase; HEX, hexokinase; PHOSPH, phosphorylase; PFK, phosphofructokinase; PK, pyruvate kinase; LDH, lactate dehydrogenase; CPK, creatine phosphokinase; ATP, adenosine triphosphate; ADP, adenosine diphosphate; AMP, adenosine monophosphate; IMP, inosine monophosphate; TAN, total adenine nucleotide; PCr, phosphocreatine; Cr, creatine; TCr, total creatine; GLUTI, glucose transporter isoform I; GLUT4, glucose transporter isoform 4; MCTI, monocarboxylate transporter isoform I; MCT4, monocarboxylate transporter 4; $\mathrm{Ca} 50$, calcium concentration necessary to elicit $50 \% \mathrm{~V}_{\max } ; \mathrm{nH}$, Hill coefficient obtained by using the relationship between $\mathrm{Ca}^{2+}$ concentration and Ca ${ }^{2+}$-ATPase activity; SR, sarcoplasmic reticulum.

Cr enabled total creatine (TCr) to be determined. We have also estimated the concentration of both free $\mathrm{ADP}\left(\mathrm{ADP}_{\mathrm{f}}\right)$ and free $\mathrm{AMP}\left(\mathrm{AMP}_{\mathrm{f}}\right)$ which is based on the near-equilibrium properties of the CPK and adenylate kinase reactions. Details including the constants and assumed concentrations and regression equation appear in an earlier publication. ${ }^{21}$ It should be noted that given the labile nature of the measured metabolites that extraction occurred on freeze-dried tissue. All properties were performed in duplicate and expressed per unit dry weight tissue. 


\section{Transporters}

The transporters measured were for glucose, GLUT1 and GLUT4, and for the monocarboxylates, MCT1 and MCT4. All transporters were assessed using electrophoresis and Western blotting techniques as described previously. ${ }^{39}$ Isoform detection was performed with an enhanced chemiluminescence procedure and the blots analyzed with a bioimaging system. For GLUT1 and GLUT4, the anti-GLUT polyclonal antisera was CBL242 and CB243, respectively, obtained from Chemicon International (Temecula, CA, USA). For MCT1 and MCT4, the antisera was AB3538P and AB3316P, respectively diluted 1:400 and also obtained from Chemicon International. All samples were run in duplicate on separate gels with CON and COPD samples matched. Protein was measured by Bio-Rad assay (Bio-Rad Laboratories, Hercules, CA, USA). Values for COPD were calculated relative to $\mathrm{CON}$ which was set at $100 \%$. The values were expressed relative to $\alpha$-actin content (used to match for protein loading) and normalized to $\mathrm{CON}$ values.

\section{$\mathrm{Na}^{+}-\mathrm{K}^{+}$-ATPase}

Two properties were measured for this enzyme, namely the maximal catalytic activity $\left(\mathrm{V}_{\max }\right)$ and the maximal content $\left(\beta_{\max }\right)$. The determination of $\mathrm{V}_{\max }$ is based on the use of an artificial substrate, namely 3-O-methylfluorsecein phosphate (3-O-MFP) which is used as a substitute for the aspartylphosphate intermediate of the enzyme. ${ }^{40}$ The catalytic activity is, in effect, determined as the measurement of the $\mathrm{K}^{+}$-stimulated 3-O-methylfluorescein phosphatase (3-O-MFP-ase), based on an assay originally developed by Nørgaard and colleagues ${ }^{40}$ and subsequently modified to produce a clear $\mathrm{V}_{\max }{ }^{41}$ Enzyme activity, using the average of three trials, was based on the slope of the reaction before and after the addition of $\mathrm{KCl}$ using fluorescence spectroscopy. Protein content of the samples was based on previously established techniques. ${ }^{37}$

For the measurement of enzyme content $\left(\beta_{\max }\right)$, the vanadate-facilitated $\left[{ }^{3} \mathrm{H}\right]$ ouabain binding technique was used..$^{42}$ A complete description of this assay, including details of the incubation buffer, corrections employed and procedural details appear in earlier publications ${ }^{43}$ This assay was conducted on two tissue samples, each weighing between 2 and $8 \mathrm{mg}$, and $\beta_{\max }$ expressed per unit wet weight.

\section{SR properties}

To characterize the SR, we have measured the catalytic properties of the $\mathrm{Ca}^{2+}$-ATPase, namely the maximal activity $\left(\mathrm{V}_{\max }\right)$, the free $\mathrm{Ca}^{2+}\left[\mathrm{Ca}^{2+}{ }_{\mathrm{f}}\right]$ needed to elicit $50 \% \mathrm{~V}_{\max }\left(\mathrm{Ca}_{50}\right)$, and the Hill coefficient (nH), defined as the slope of the relationship between $\mathrm{Ca}^{2+}$-ATPase activity and $\left[\mathrm{Ca}^{2+}\right]_{\mathrm{f}}$ These measurements were also supplemented by determinations of $\mathrm{Ca}^{2+}$-uptake and $\mathrm{Ca}^{2+}$-release. By measuring $\mathrm{V}_{\text {max }}$, with and without the $\mathrm{Ca}^{2+}$ ionophore, A-23187, we were able to calculate the ionophore ratio which provides an indirect measure of the integrity of the SR membrane for $\mathrm{Ca}^{2+} \cdot{ }^{44}$ The coupling ratio, determined by the ratio of $\mathrm{Ca}^{2}$-uptake to $\mathrm{V}_{\text {max }}$, provides an index of the energetic efficiency of $\mathrm{Ca}^{2+}$-sequestration into the SR.44

Enzyme activity was measured at $37{ }^{\circ} \mathrm{C}$ using a spectrophotometric method ${ }^{44}$ as modified by our group. ${ }^{45}$ In this assay, the $\mathrm{Ca}^{2+}$-dependent activity of the enzyme is obtained by subtracting the $\mathrm{Ca}^{2+}$-independent activity or basal activity. The basal activity is obtained using cyclopiazonic acid, which completely inhibits the $\mathrm{Ca}^{2+}$-ATPase activity. ${ }^{46}$ The $\mathrm{Ca}^{2+}$-uptake and $\mathrm{Ca}^{2+}$-release was measured during the same assay as described. ${ }^{45}$ With our protocol, we observed two phases of $\mathrm{Ca}^{2+}$-release which we labeled phase I and phase II. ${ }^{45}$ Phase I represents the initial fast phase of release while phase II is a slower more delayed phase. ${ }^{45}$ It should be noted that, unlike the $\mathrm{Ca}^{2+}$-ATPase which can be measured on frozen tissue with minimal loss of activity, $\mathrm{Ca}^{2+}$-uptake and $\mathrm{Ca}^{2+}$-release must be measured on homogenates prepared on fresh tissue which can then be stored.

To measure the level of $\left[\mathrm{Ca}^{2+}\right]_{\mathrm{f}}$, which these assays depend on, dual-wavelength spectrofluorometry and the $\mathrm{Ca}^{2+}$-fluorescent dye, indo-1 was employed. Additional details appear in earlier publications from our laboratory. ${ }^{45}$ Where possible all measurements were performed in duplicate and care was taken to ensure that CON and COPD samples were matched in a given analytical session. As in previous measurements, the values were expressed per unit protein with protein assessed as described. ${ }^{37}$

\section{Results Histochemistry}

Clear differences were observed in the distribution of the fiber types and subtypes between the healthy, control participants and the two COPD patients (Table 3). The COPD patients displayed a pronounced lower percentage of type I fibers. The increase in the type II fiber percentage observed in COPD was distributed in both the type IIA and the type IIAX for both patients. Type IIX fibers were noted to be elevated in COPD \#1 but not COPD \#2. The percent of the type IC and type IIC only ranged between $0.5 \%$ to $3 \%$ in CON. Type IC fibers was observed to increase to $6.7 \%$ in COPD \#1 while no type IIC fibers were detected in COPD \#2.

Differences were also noted between the healthy and diseased subjects in the areas of the different fiber 
Table 3 Selected histochemical properties in tissue obtained from the vastus lateralis muscle of two patients with chronic obstructive pulmonary disease and healthy controls

\begin{tabular}{|c|c|c|c|c|c|c|}
\hline & \multicolumn{6}{|l|}{ Fiber type } \\
\hline & $I$ & IC & IIC & IIA & $\operatorname{IIAX}$ & IIX \\
\hline \multicolumn{7}{|c|}{ Distribution (\%) } \\
\hline $\mathrm{CON}$ & $57.3 \pm 5.2$ & $0.50 \pm 0.23$ & $3.0 \pm 2.4$ & $27.9 \pm 0.44$ & $3.1 \pm 1.7$ & $8.2 \pm 4.3$ \\
\hline COPD \#I & 16.7 & 6.7 & 2.7 & 37.3 & 11.3 & 25.3 \\
\hline COPD \#2 & 24.9 & 0.5 & 0.0 & 49.3 & 17.8 & 7.5 \\
\hline \multicolumn{7}{|c|}{ SDH (OD units) } \\
\hline $\mathrm{CON}$ & $0.16 \pm 0.02$ & & & $0.14 \pm 0.04$ & $0.15 \pm 0.05$ & $0.14 \pm 0.03$ \\
\hline COPD \#I & 0.18 & & & 0.16 & 0.14 & 0.12 \\
\hline COPD \#2 & 0.21 & & & 0.17 & 0.18 & 0.13 \\
\hline \multicolumn{7}{|c|}{$\mathrm{Ca}^{2+}$-ATPase (OD units) } \\
\hline $\mathrm{CON}$ & $0.10 \pm 0.02$ & & & $0.31 \pm 0.04$ & $0.29 \pm 0.04$ & $0.36 \pm 0.07$ \\
\hline COPD \#I & 0.13 & & & 0.30 & 0.30 & 0.37 \\
\hline COPD \#2 & 0.07 & & & 0.15 & 0.24 & 0.33 \\
\hline
\end{tabular}

Notes: Values are $\bar{x} \pm S E$. For $C O N, \mathrm{n}=4$.

Abbreviations: CON, control; COPD \#I and COPD \#2, two chronic obstructive lung disease patients. Distribution, \% distribution of different fiber types; SDH, succinic dehydrogenase activity; $\mathrm{Ca}^{2+}$-ATPase, $\mathrm{Ca}^{2+}$-ATPase activity.

types (Figure 1). In the case of the type I fibers, the area was between $35 \%$ to $38 \%$ lower in COPD. For the type II fiber types, clear differences existed between the COPD patients. For COPD \#1, areas ranged between $89 \%$ (IIA), $83 \%$ (IIAX), to $74 \%$ (IIX) of CON. Such was note the case for COPD \#2 where the areas were only $17 \%$ (IIA) and 32\% (11AX and IIX) of CON. The capillary counts also suggested a heterogenous response between the COPD patients. In general, the capillary counts were better protected in COPD \#2 compared to COPD \#1. Compared to CON, the capillary counts in type I were lower by $59 \%$ and increased by $28 \%$ in COPD \#1 and COPD \#2, respectively. For the type II subtypes, comparative reductions were $56 \%$ and $30 \%$ for IIA, 39\% and $0 \%$ for IIAX, and $68 \%$ and $9 \%$ for IIX in COPD \#1 and COPD \#2, respectively.

A contrasting profile also existed for the capillary-to-fiber area ratio properties in the two COPD volunteers. For COPD \#1, the ratio was lower than CON regardless of fiber type, with observed differences of $61 \%, 48 \%, 72 \%$, and $41 \%$ observed for I, IIA, IIAX, and IIX, respectively. In contrast, for COPD \#2, the capillary-to-fiber area ratio was 1.8-, 4-, 3.2-, and 2.8-fold higher of CON for I, IIA, IIAX, and IIX, respectively as a result of the severe atrophy that occured.

We have also measured the activity of $\mathrm{SDH}$ and the $\mathrm{Ca}^{2+}$-ATPase in fiber-specific types of CON and COPD (Table 3). In general, SDH activity was not substantially different between the COPD individuals and the CON. For COPD \#2, there was a trend for the activities to be higher in most fiber types as indicated by the approximately $20 \%$ to $23 \%$ higher activity observed in the type I, IIA, and IIAX fibers. In contrast to SDH activity, $\mathrm{Ca}^{2+}$-ATPase ${ }^{2+}$ activity was clearly depressed in COPD \#2 compared to CON, the magnitude of the decrease depending on the fiber type (Table 3). For this patient, the decrease observed was most pronounced for the type I and type IIA fibers, representing $30 \%$ and $52 \%$ of CON, respectively. For the type IIAX and type IIX fibers, the decreases were only $17 \%$ and $8 \%$ of CON, respectively.

\section{Biochemistry}

\section{Transporters}

The relative levels of GLUT1 and GLUT4 were well protected in COPD \#1, but not in COPD \#2 (Figure 2). In COPD \#2, GLUT1 and GLUT4 were $71 \%$ and $54 \%$ of CON, respectively. In contrast to the GLUT in COPD \#1, both MCT1 and MCT4 were subnormal which in the case of MCT1 was 37\% and in the case of MCT4 was 22\%. A 59\% lower MCT1 content was also observed for COPD \#2. Unfortunately, no values are available for MCT4 for this patient.

\section{Enzymes}

Both the mitochondrial and the cytosolic enzyme activities were all lower in COPD \#2 compared to CON (Figures 3A, 3B). For the enzymes of the CAC, CS, SDH, and $\mathrm{MDH}$ were reduced by $47 \%, 63 \%$, and $49 \%$, respectively. 

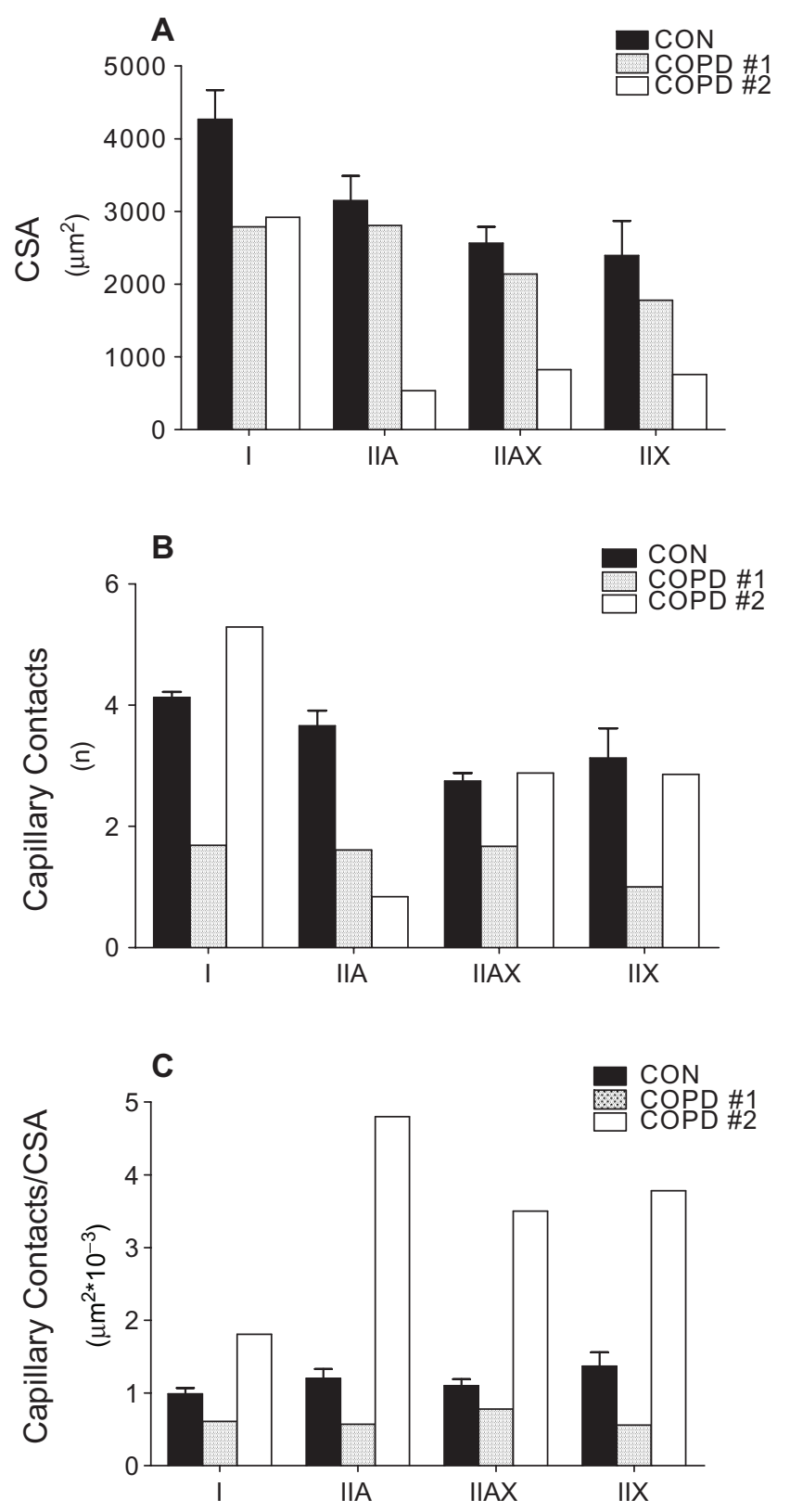

Figure I Fiber-specific histochemical properties in tissue obtained from vastus lateralis muscle in healthy volunteers and two patients with advanced chronic obstructive pulmonary disease.

Notes: For CON, values are means \pm SE $(n=4)$.

Abbreviations: CON, control; COPD \#I and COPD \#2, two chronic obstructive pulmonary disease patients; I, IIA, IIAX, IIX, fiber types and subtypes; CSA, cross-sectional area; capillary counts, number of capillaries \pm around a fiber; capillary contacts/CSA number of capillaries around a fiber divided by the CSA; SE, standard error.

This compared to a $30 \%$ lower activity for COX, the ETC complex measured. For the cytosolic enzymes, the greatest reduction in activity was observed for PHOS (63\%) and PK (69\%) followed by PFK (31\%), CPK (32\%), LDH (17\%), and HEX (11\%). Protein concentration (mg/g) was $206 \pm 4.9$ for CON and 153 for COPD \#2, a difference of $26 \%$. No tissue was available for the enzyme measurements in COPD \#1.

\section{Substrate and metabolites}

COPD was accompanied by reductions in phosphorylation potential as indicated by the lower concentrations of the high-energy phosphagen compounds (Table 4). For ATP, the reductions ranged between $22 \%$ to $24 \%$ for the two patients while reductions in TAN ranged between $17 \%$ and $22 \%$ in the COPD patients. For COPD \#2, there was an approximately threefold higher IMP concentration than CON. For COPD \#1, IMP appeared normal. Comparable reductions of between $17 \%$ and $20 \%$ in the COPD participants were observed for PCr (Table 4). Only in COPD \#2 was there a suggestion that $\mathrm{TCr}$ was reduced (13\%) as well. Overall phosphorylation potential was $80 \%$ and $83 \%$ of CON for COPD \#1 and COPD \#2, respectively. With regards to the endogenous carbohydrate substrate, glycogen, COPD \#1 appeared able to maintain and even increase (19\%) storage while COPD \#2 showed a substantial reduction (24\%). Lactate concentration was within a normal range for both patients.

\section{Cation cycling}

Measurements were performed on the $\mathrm{Na}^{+}-\mathrm{K}^{+}$-ATPase for determinations of maximal activity $\left(\mathrm{V}_{\max }\right)$ and maximal content $\left(\beta_{\max }\right)$ (Table 5). For $\mathrm{V}_{\max }$, a reduction of $34 \%$ was observed in COPD \#1 while the $\mathrm{V}_{\text {max }}$ for COPD \#2 was the normal range (92\%). Both patients displayed changes in $\beta_{\max }$ with COPD \#1 and COPD \#2 with values approximately $20 \%$ lower and higher, respectively.

For $\mathrm{Ca}^{2+}$-ATPase, $\mathrm{V}_{\max }$ was modestly lower (16\%) as was the $\mathrm{Ca}^{2+}$-uptake (14\%) for COPD \#1 (Table 5). Interestingly, for this patient differences were clearly evident in the $\mathrm{Ca}^{2+}$ sensitivity of the enzyme with $\mathrm{Ca}_{50}$ and $\eta_{\mathrm{H}}$ being higher and lower, respectively in the disease state. Only small differences $(9 \%)$ observed in the ionophore ratio and no difference in the coupling ratio. There was a suggestion of a reduced $\mathrm{Ca}^{2+}$-uptake for phase I (18\%) but not phase II (5\%).

\section{Discussion}

In this study, our primary aim was to provide a current review of the advances that have occurred in muscle physiology and biochemistry, both with regards to the proteins and processes regulating contractile function and the analytical techniques available for measurement. To highlight clinical relevance, we have provided the most comprehensive and integrated profile of a wide range of muscle properties ever performed on COPD patients. To contrast the different effects of COPD on muscle, we have selected two COPD patients with advanced COPD disease but differing in the degree of cachexia. Dual energy X-ray (DEXA) to measure body composition ${ }^{26}$ was 


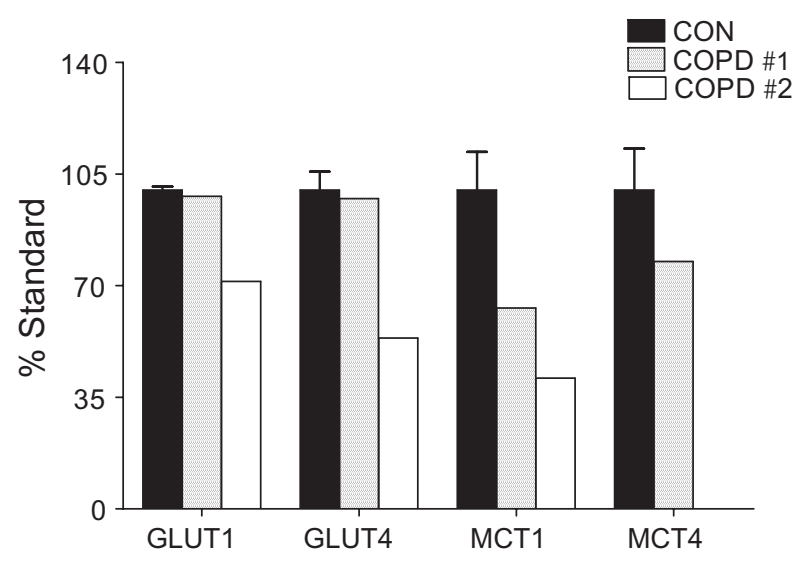

Figure 2 Relative contents of glucose and monocarboxylate transporters in healthy volunteers and two patients with advanced chronic obstructive pulmonary disease. Notes: For CON, values are means \pm SE.

Abreviations: \% Standard, percent change first calculated against a standard and then calculated as a relative change from 100\% (CON); GLUTI and GLUT4, glucose transporter isoforms, GLUTI and GLUT4, respectively; MCTI and MCT4, monocarboxylate isoforms, MCTI and MCT4, respectively; SE, standard error.

applied to confirm differences between COPD \#1 and COPD \#2 in lean body mass. Our objective was to address both the processes involved in ATP production (metabolic pathways) and the processes involved in ATP utilization with emphasis on cation cycling.

To-date, studies designed to identify the underlying mechanisms involved in muscle weakness and fatigue so prevalent in COPD have almost exclusively concluded that disproportionate increases in lactate during contractile activity is due, at least in part, to deficiencies in oxidative potential. In general, these conclusions have been based on the lower $\mathrm{V}_{\max }$ of a single enzyme of the CAC. It is our hypothesis, that identification of mechanisms for muscle mechanical failure and abnormal metabolic response must include a broader range of measurements, including those involved in cation cycling and substrate and metabolic by-product transport. Our findings using two patients clearly indicate that this is the case. A critical issue relates to the mechanisms underlying the different phenotype observed in the vastus lateralis in the COPD patients. Such mechanisms must be able to account both for the properties that are common to both patients and the properties that were differentially expressed. In the following sections, we categorize and review the properties affected.

\section{Histochemistry}

A common and expected response was the large increase in the percentage of the fast-twitch, type II fibers and the decrease in the slow-twitch, type I fiber percent observed in both patients in this study and our earlier study. ${ }^{26}$ The change in the fiber type profile in COPD which has been observed many times previously ${ }^{2,4}$ has been attributed to a simple transformation of fiber types. ${ }^{3}$ Since the histochemical identification of the different fiber types is based on the myosin heavy chain isoforms, ${ }^{48}$ the shift would have to involve both the isolated expression of a single isoform, namely HCIIA or HCIIX in the case of the IIA and IIX fibers, respectively or the co-expression of more than one isoform such as IIA and IIX in hybrid fibers (IIAX). In addition, the expression of the HCI isoform would have to be either partially (IC, IIC) or completely inhibited (IIA, IIX, IIAX). Although, such a transformation is possible particularly in conditions such as spinal cord injury, ${ }^{49}$ it has not been observed, at least to a comparable extent, in physiological settings, involving profound reductions in contractile activity ${ }^{50}$ or hypoxic environments. ${ }^{51}$ Another possible explanation to account for the alteration in fiber type distribution in COPD is a selective apoptosis of the type I fiber pool. There is increasing evidence to indicate that apoptosis does occur, particularly in severe $\mathrm{COPD}^{23}$ and that the type I fibers may be selectively targeted. ${ }^{23}$ However, in multinucleated cells such as the myocyte, apoptosis appears to induce only atrophy. ${ }^{23}$

Atrophy was pronounced in the type I fibers in both patients to a similar degree. However, only in COPD \#2 was a predominant atrophy found in the type II fiber subtypes. This patient also had the lowest body weight and BMI, which appears to be primarily determined by the atrophy that occurs. ${ }^{2}$ Muscle atrophy has also been reported in previous studies, however the fiber population affected appears in dispute since one study has reported only a selected effect on the less oxidative type II subtypes (IIAX and IIX) ${ }^{52}$ while another study has found that the type I and the more oxidative fibers (IIA and IIAX) are selectively affected..$^{53}$ Our study suggests that the fiber-type specific pool affected may depend on the amount of muscle wasting that occurs. It is also possible that the effect on specific fiber types may be affected by gender. ${ }^{26}$

It is clear that increased capillarization of the muscle fiber was not an adaptive response to advanced COPD since no increase in the number of capillaries was observed in either patient. Muscle wasting was related to a protective effect since COPD \#2 who had the lowest BMI, with the exception of type IIA, maintained a normal number of capillaries per fiber while COPD \#1, the patient with a normal BMI, displayed a pronounced reduction in capillaries in all fiber types and subtypes. The results observed for COPD \#2 are generally consistent with an earlier study which also reported lower capillarity in the different fiber pools..$^{53}$ The ratio of the CC per unit CSA, a structural index of perfusion 
A

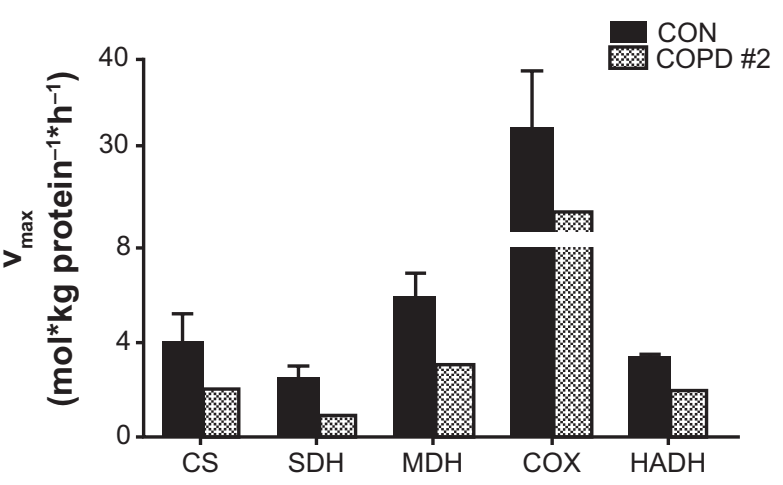

B

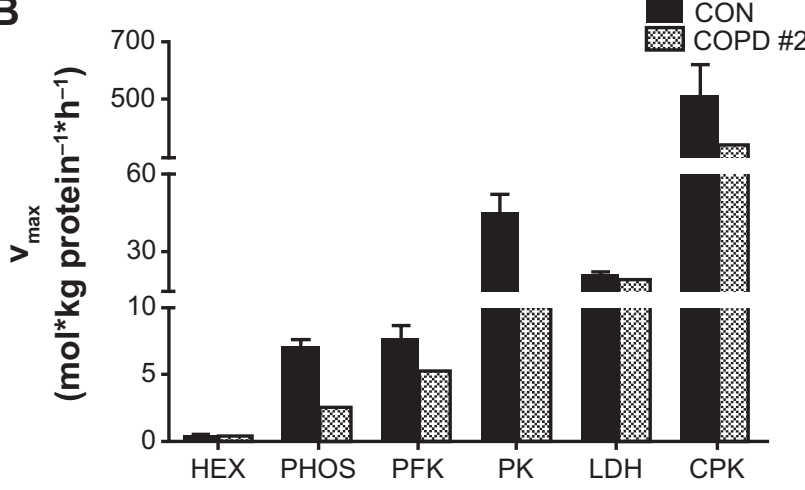

Figure 3 Maximal activities of mitochondrial $\mathbf{A}$ ) and cytosolic $\mathbf{B}$ ) enzymes in vastus lateralis muscle of healthy volunteers and a patient with advanced chronic obstructive pulmonary disease.

Notes: For CON, Values are means \pm SE $(n=4)$.

Abbreviations: CON, control; COPD \#2, patient with chronic obstructive pulmonary disease. $V_{\max }$, maximal enzymatic activity; $\mathrm{CS}$, citrate synthase; $\mathrm{SDH}$, succinic dehydrogenase; $\mathrm{MDH}$, malate dehydrogenase; COX, cytochrome c oxidase; $\mathrm{HADH}$, 3-hydroxyacyl-CoA dehydrogenase; HEX, hexokinase; PHOS, phosphorylase; PFK, phosphofructokinase; PK, pyruvate kinase; LDH, lactate dehydrogenase; CPK, creatine phosphokinase; SE, standard error.

potential, ${ }^{25}$ was compromised in COPD \#1 and increased in COPD \#2 by primarily different mechanisms. In COPD \#1, the increase was mediated primarily by the disproportionate reductions in the number of capillaries while in COPD $\# 2$, the improved response occurred basically as a result of the more pronounced reduction in CSA. The latter response is typical to that observed during altitude acclimatization where fiber atrophy is present without changes in angiogenesis. ${ }^{51}$

\section{Biochemistry}

The most common defect observed in the muscle of COPD patients is a lower activity of CS $\mathrm{CS}^{13,14,16,54}$ and in isolated studies, $\mathrm{SDH},{ }^{16}$ which has been used to support a diagnosis of a reduced potential for oxidative phosphorylation. ${ }^{3}$ Moreover, not all studies have reported reductions in CS with COPD.$^{55}$ For COPD \#2, the patient with the low BMI, it is clear that not only is CS reduced, but the reduction extends to all of the other CAC and ETS enzymes and complexes studied. Moreover, unlike earlier studies which have not reported differences between the healthy and COPD groups in the limited number of cytosolic enzyme activities, ${ }^{14,54}$ we found that in this patient the regulatory enzymes of glycogenolysis and glycolysis, namely PHOS and PFK, were substantially lower. However, the reductions did not extend to all cytosolic enzymes since HEX and LDH were normal, indicating a preserved capacity for glucose phosphorylation and lactate oxidation. These differences contradict an earlier study which has found elevations in PFK and possibly LDH in patients with severe COPD. ${ }^{16}$ Interestingly in this study, BMI was protected. The protection of muscle mass and fiber CSA may be important in the changes observed in the cytosolic enzymes since many are bound to the myofibrillar proteins, ${ }^{56}$ which undergo the degradation. Unfortunately, the lack of tissue prevented enzyme measurements in COPD \#1. Given the fact that the activity of SDH, measured microphotometry, was normal in this patient, it is possible that oxidative potential was not compromised. In a related study from this project, among the mitochondrial and cytosolic enzymes examined, alterations in $\mathrm{V}_{\text {max }}$ in only COX and HADH (reductions) and HEX (increase) were observed in moderate to severe COPD patients. ${ }^{18}$ It appears that multiple factors, including disease severity, may alter the individual enzyme response and the potential of the metabolic pathways and segments.

A unique feature of the current study was the measurement of the glucose and monocarboxylate transporters, only previously measured in muscle of COPD patients in a recent study from our group. ${ }^{21}$ In this earlier study, we have reported that GLUT4 and MCT4 were depressed while GLUT1 and MCT1 were normal. These results indicate that abnormalities in the content of the transporters may also contribute to the disturbances in the metabolic responses to contractile activity. In COPD \#2, the patient with the low BMI, the ability to transport glucose across the cell membrane, both during exercise and recovery, would be expected to be compromised given the much lower content of GLUT1 and GLUT4. ${ }^{19}$ Moreover, the reduced level of MCT1, the minor isoform primarily involved in facilitating lactate into the cell ${ }^{57}$ would be expected to impair the distribution of lactate and $\mathrm{H}^{+}$ to other tissues. No measurements are available for MCT4, the principal isoform, which functions to transport lactate and $\mathrm{H}^{+}$out of the cell where it is generated..$^{57}$ In COPD \#1, both MCT1 and MCT4 were depressed with the greatest reduction observed for MCT1. In this patient, the potential for glucose transport was unaffected, given the normal levels of both GLUT1 and GLUT4. 
Table 4 The concentration of high-energy phosphates and metabolites, glycogen and lactate in vastus lateralis muscle of healthy control subjects and two patients with chronic obstructive pulmonary disease

\begin{tabular}{llll}
\hline & CON & COPD \#I & COPD \#2 \\
\hline $\begin{array}{llll}\text { Glycogen } \\
\text { (mmol (glucose/units. kg }\end{array}$ & $261 \pm 26$ & 310 & 198 \\
ATP (mmol. $\mathrm{kg}^{-1}$ d.w.) & & & \\
ADP & $22.1 \pm 0.54$ & 17.3 & 16.9 \\
AMP & $3.34 \pm 0.19$ & 2.60 & 4.32 \\
TAN & $0.08 \pm 0.01$ & 0.034 & 0.156 \\
IMP & $25.5 \pm 0.71$ & 19.9 & 21.3 \\
PCr & $0.10 \pm 0.03$ & 0.07 & 0.32 \\
Cr & $83.8 \pm 4.1$ & 66.9 & 69.0 \\
TCr & $49.6 \pm 2.5$ & 60.2 & 46.2 \\
PP & $133 \pm 1.8$ & 127 & 115 \\
Lactate & $109 \pm 3.6$ & 86.8 & 90.3 \\
\hline
\end{tabular}

Notes: Values are $\bar{x} \pm S E$. For CON, $n=4$. With the exception of glycogen, the units for all properties are mmol. $\mathrm{kg}^{-1}$ d.w.

Abbreviations: CON, control; COPD \#I and COPD \#2, two chronic obstructive lung disease patients; ADP, adenosine diphosphate; AMP, adenosine monophate; TAN, total adenine nucleotide; IMP, inosine monophosphate; $\mathrm{PCr}$, phosphocreatine; $\mathrm{Cr}$, creatine; $\mathrm{TC}$, total creatine; PP, phosphorylation potential.

It is apparent that even with the depression in both the glucose and monocarboxylate transporters in COPD \#2, glycogen and lactate concentrations in resting muscle were only modestly reduced (glycogen) or unaffected (lactate). In COPD \#2, a modest supercompensation in glycogen was observed accompanied by modest elevations in resting lactate. It is emphasized that the transporters represent but one among many factors governing regulation. ${ }^{19,20}$

Since muscle contractility is intimately dependent on the viability of the $\mathrm{E}-\mathrm{C}$ coupling processes, we have also measured several properties regulating cation exchange across the sarcolemma and t-tubule and the SR. The $\mathrm{V}_{\max }$ of the $\mathrm{Na}^{+}-\mathrm{K}^{+}$-ATPase, which regulates the active transport of $\mathrm{Na}^{+}$ and $\mathrm{K}^{+}$, was normal in COPD \#2 and reduced in COPD \#1. The lower $\mathrm{V}_{\text {max }}$ in COPD \#1 could be explained by the lower $\mathrm{Na}^{+}-\mathrm{K}^{+}$-ATPase content. The reason for the different response pattern between the patients is not clear. However, the greater atrophy observed in the type fiber subtypes in COPD \#2 may have some influence. Since this cation pump is distributed in both in the sarcolemma and t-tubule and the cytosol, ${ }^{58}$ the greater loss of myofibrillar protein with atrophy could result in an apparent increase in pump concentration since we have expressed our results relative to total protein content. Chronic hypoxia is known to depress the content of the pump ${ }^{59}$ which could be important given the arterial hypoxemia that exists in COPD. However, this would not appear to explain the different responses observed since the patients were generally comparable in pulmonary function. The lower catalytic activity of the $\mathrm{Na}^{+}-\mathrm{K}^{+}$-ATPase observed in COPD \#1 may provide a rationale for the impaired membrane excitability previously shown to occur in COPD. ${ }^{60}$ Moderate to severe COPD also is accompanied by a reduction in muscle $\mathrm{V}_{\text {max }}$, due possibly to isoform shifts since the content of enzyme was unchanged. ${ }^{6}$

We have reported that disturbances in SR calcium cycling in muscle may accompany COPD given the depression in $\mathrm{Ca}^{2+}$-uptake observed which appears to be mediated by the lower $\mathrm{V}_{\max }$ of the $\mathrm{Ca}^{2+}$-ATPase. ${ }^{5}$ The reduction in $\mathrm{Ca}^{2+}$-uptake was not accompanied by disturbances in the two phases of $\mathrm{Ca}^{2+}$-release. Perhaps of greater significance than the modest reductions in $\mathrm{Ca}^{2+}$-uptake observed was the changes that occurred in the $\mathrm{Ca}^{2+}$-sensitivity of the enzyme. ${ }^{5}$ The reduction in $\mathrm{Ca}^{2+}$-sensitivity, as indicated by both the $\mathrm{Ca}_{50}$ and the $\eta_{\mathrm{H}}$, could have important functional implications since to obtain a given catalytic activity and consequently a given $\mathrm{Ca}^{2+}$-uptake, elevations in $\mathrm{Ca}^{2+}$ or changes in second messenger regulation would appear necessary. ${ }^{61}$ The change in the $\mathrm{Ca}^{2+}$-sensitivity of the enzyme suggests that structural alterations may have occurred to the enzyme ${ }^{61,62}$ and/ or alterations in regulatory behavior. ${ }^{47}$ Membrane integrity and the efficiency of $\mathrm{Ca}^{2+}$ cycling, as measured by the ionophore ratio and coupling ratio were normal. Essentially, the same changes in the SR occurred in COPD \#1. In COPD \#2, no biochemical measurements of the SR were possible. However, based on the microphotometric assessments, a pronounced depression in $\mathrm{V}_{\max }$ of the enzyme is clearly indicated based on the lower activity measured, particularly in the type I and type IIA fibers. It is possible that the depression in the $\mathrm{Ca}^{2}$-ATPase may be even more depressed in COPD \#2 than COPD \#1 since an earlier report has found that the severity is related to a lower BMI. ${ }^{63}$ Since precise regulation in $\mathrm{Ca}^{2+}{ }_{\mathrm{f}}$ is important in defending against fatigue during contractile activity, ${ }^{64}$ it is conceivable that the SR could be implicated in the failure of muscle in COPD patients to function normally.

A critical condition in the ability of muscle to maintain normal function is the protection of energy homeostasis. Maintenance of normal muscle energy levels is particularly challenging in COPD where oxygen availability to the muscle cell may be compromised. ${ }^{12}$ Energy homeostasis is dependent in part, on the phosphorylation potential, represented as the sum of the concentrations of the adenine nucleotides and the phosphocreatine. Both COPD patients displayed an inability to maintain a normal phosphorylation 
Table 5 A comparison between healthy controls and two patients with chronic obstructive pulmonary disease on selected properties of the sarcoplasmic reticulum and the $\mathrm{Na}^{+}-\mathrm{K}^{+}$-ATPase in tissue obtained from the vastus lateralis muscle

\section{CON COPD\#I COPD \#2}

SR

\begin{tabular}{|c|c|c|c|}
\hline \multicolumn{4}{|l|}{$\mathrm{Ca}^{2+}$-ATPase } \\
\hline $\mathrm{V}_{\max }\left(\mu \mathrm{mol} . \mathrm{g} \mathrm{pro}^{-1} \cdot \mathrm{min}^{-1}\right)$ & $175 \pm 13$ & 147 & NA \\
\hline $\mathrm{Ca}_{50}(\mathrm{nM})$ & $883 \pm 51$ & 1445 & NA \\
\hline $\mathrm{nH}$ & $2.17 \pm 0.05$ & 153 & NA \\
\hline Lonophore ratio & $3.3 \pm 1.3$ & 3.7 & NA \\
\hline $\mathrm{Ca}^{2+}$-uptake $\left(\mu \mathrm{mol} . \mathrm{g} \mathrm{pro}^{-1} \cdot \mathrm{min}^{-1}\right)$ & $5.04 \pm 1.2$ & 4.32 & NA \\
\hline Coupling ratio & $0.029 \pm 0.01$ & 0.029 & NA \\
\hline \multicolumn{4}{|l|}{$\mathrm{Ca}^{2+}$-release $\left(\mu \mathrm{mol} . \mathrm{g} \mathrm{pro}^{-1} \cdot \mathrm{min}^{-1}\right)$} \\
\hline Phase I & $20 \pm 0.26$ & 16.4 & NA \\
\hline Phase 2 & $5.39 \pm 1.7$ & 5.11 & NA \\
\hline \multicolumn{4}{|l|}{$\mathrm{Na}^{+}-\mathrm{K}^{+}$-ATPase } \\
\hline$\beta_{\max }\left(\right.$ pmol.g wet $\left.w^{-1}\right)$ & $283 \pm 36$ & 228 & 336 \\
\hline $\mathrm{V}_{\max }\left(\mathrm{nmol} \cdot \mathrm{mg} \mathrm{pro}^{-1} \cdot \mathrm{h}^{-1}\right)$ & $93.1 \pm 8.0$ & 61.9 & 85.9 \\
\hline
\end{tabular}

Notes: Values are $\bar{x} \pm S E$. For CON, $\mathrm{n}=4$ for $\mathrm{Na}^{+}-\mathrm{K}^{+}-$ATPase and $\mathrm{n}=2$ for $S R$. Abbreviations: CON, control; COPD \#I and COPD \#2, two chronic obstructive pulmonary disease patients; $\mathrm{SR}$, sarcoplasmic reticulum; $\mathrm{V}_{\text {, }}$, maximal catalytic activity; $\mathrm{Ca}_{50}, \mathrm{Ca}^{2+}$ concentration needed to elicit $50 \%$ maximal $\mathrm{Ca}^{2+}$-ATPase activity; $\mathrm{n}_{\mathrm{H}}$, Hill coefficient, as determined from Hill plots using the relationship between free $\mathrm{Ca}^{2+}$ concentration and $\mathrm{Ca}^{2+}$-ATPase activity and the section of the curve that corresponds to $10 \%-90 \%$ maximal $\mathrm{Ca}^{2+}$-ATPase activity; lonophore ratio, ratio between $\mathrm{V}_{\max }$ determined with and without the $\mathrm{Ca}^{2+}$-ionophore, A-23 |87; Coupling ratio, ratio of $\mathrm{Ca}^{2+}$-uptake to $\mathrm{V}_{\text {max }} ; \mathrm{Ca}^{2+}$-release, calculated as a fast (Phase I) and slow phase (Phase 2); $\beta_{\text {max }}$ maximal enzyme content as measured by the $\left[{ }^{3} \mathrm{H}\right]$ oubain binding procedure; $\mathrm{V}$ maximal catalytic activity as measured by the 3-O-methyl fluorescein phosphatase (3-O-MFPase) assay; NA, not available.

potential, a finding that we have reported previously in patients with moderate to severe COPD. ${ }^{21}$ The pool size of both the adenine nucleotides and total creatine were reduced, possibly as a consequence of the degradation to IMP and inosine with subsequent loss from the cell. ${ }^{65} \mathrm{~A}$ similar response has been previously reported in COPD. ${ }^{66,67}$ Given the relatively low ATP demands that occur in muscle at rest, it is curious that normal phosphorylation potentials cannot be maintained. It has been suggested that the primary problem occurs a result of mitochondrial dysfunction which results in a reduction in the $\mathrm{P} / \mathrm{O}$ ratios and loss of efficiency. ${ }^{23}$ The reserves of the endogenous substrate, glycogen, would appear not to be a factor since glycogen was within the normal ranges in both patients.

\section{Perspectives and significance}

In summary, in this paper we have provided an overview of the current state of knowledge on the factors regulating contractile behavior in the muscle cell. We also provide a brief review of what is known regarding the abnormalities that occur in muscle in COPD, an area that merits deeper investigation, given the weakness and fatigue that accompanies COPD. To promote clinical interest, we present the results obtained from two case studies in which an extensive profile of muscle properties was obtained. As a practical benefit, aimed at facilitating the inclusion of muscle-based assessment into clinical practice, we provide information on tissue sampling and on the analytical techniques employed for the measurement of specific properties. It is emphasized that the results of the two case studies are for purposes of illustration only. Conclusions regarding the type and magnitude of specific muscle abnormalities, both with regard to disease severity and associated side effects, such as cachexia, depend on the completion of many more studies with much larger sample sizes. It is also emphasized that given the limited amount of tissue available, some of the analytical profiles completed within each of the muscle characteristics addressed is by necessity incomplete. Regardless, based on the measurements completed, it is inviting to speculate on the potential implications of the abnormalities that were observed in the COPD patients with regard to weakness and fatigue.

Weakness and fatigue are general terms, used to broadly indicate deficiencies in neuromuscular function. The term "weakness" has been defined as a persistent disturbance in force-generating capacity while "fatigue" is a loss in the capability to generate an expected force when provoked by repetitive contractions ${ }^{64}$ It is important to emphasize that during voluntary effort, the origin of weakness and fatigue may be central (neural) as a result of an inability to fully activate the motoneuron pool, both within and between synergistic muscles, peripheral (muscle) as a consequence of intrinsic abnormalities in the muscle fiber itself or a combination of both central and peripheral. At present, the locus of weakness and fatigue in COPD has been given little attention.

The characterization of weakness and fatigue may also be task-dependent, influenced by the specific demands imposed on the neural and muscular components. Tasks may be generally subdivided into those which are conducted at constant muscle length (isometric) and into those in which movement or velocity is involved (dynamic). From a muscle perspective, the intrinsic properties of the excitation and contraction processes in the cell represent the primary determinants of mechanical behavior.

Given the abnormalities observed in the two COPD patients included in this paper several effects on weakness and fatigue should occur. The shift in the fiber types towards a greater proportion of type II fibers accompanied 
by a reduction in type I fibers, would be expected to promote tasks performed at high velocity as a result of the increase in the fast myosin heavy chain isoforms. ${ }^{10}$ However, the muscle atrophy observed would compromise force-generating capacity both during isometric and dynamic contractions. ${ }^{10}$ The resulting weakness would in itself promote a more rapid fatigue compared to healthy individuals during repetitive tasks performed at a given absolute requirement.

To preserve contractile function during submaximal repetitive activity, the muscle cell must be able to respond to each of the neural impulses by generating an action potential and conducting the action potential on the surface of the fiber and into the interior of the fiber by the sarcolemma amd t-tubule, respectively. During submaximal contractions, the impulse frequency could be in the range of $10-20 \mathrm{~Hz}$. The integrity of the action potentials depends on re-establishing the resting membrane potential between each excitation, a condition which depends on the active transport of $\mathrm{Na}^{+}$ and $\mathrm{K}^{+}$, and the restoration of the transmembrane gradients for each cation. This function is, in large part, determined by the catalytic activity of the $\mathrm{Na}^{+}-\mathrm{K}^{+}$-ATPase. ${ }^{58}$ It is clear that in COPD \#1, the maximal catalytic activity was depressed, a condition that could result in an inability to generate repetitive action potentials. If such was the case, communication with the SR would be compromised, $\mathrm{Ca}^{2+}$-release reduced, $\mathrm{Ca}^{2+}$-induced myofibrillar activation disrupted and fatigue accelerated. ${ }^{61}$

Intrinsic alterations at the level of the SR itself may also alter the mechanical response to sustained activity. For COPD \#1, on whom we have been able to measure several SR properties, it is clear that abnormalities exist, particularly with the $\mathrm{Ca}^{2+}$-uptake function of the SR. The reduction in $\mathrm{Ca}^{2+}$-uptake observed in this patient would be expected to promote reductions in the relaxation rate in the fiber after a contraction, which could, depending on the activation level, result in a reduction in $\mathrm{Ca}^{2+}$-release. Reductions in $\mathrm{Ca}^{2+}$-release, leading to a depression in the concentration of cytosolic-free $\mathrm{Ca}^{2+}$, have been identified as a primary cause of fatigue during submaximal activity characterized by a relatively low frequency of activation (low frequency fatigue). ${ }^{64}$ In addition to the reduction in $\mathrm{Ca}^{2+}$-uptake observed in this patient, abnormalities were also found in the regulatory behavior of the enzyme. The loss of $\mathrm{Ca}^{2+}$-sensitivity, as an example, unless compensated for, would have important implications to the cytosolic-free $\mathrm{Ca}^{2+}$ needed to achieve a desired $\mathrm{Ca}^{2+}$-uptake.

The alterations in energy-producing machinery within the cell observed in the patients may also impact on tasks requiring sustained activity. At rest, the energy charge in the cell in both patients is only modestly impaired. Consequently, given the relatively small requirements of a brief contraction on the high-energy phosphagens, it would not be expected that force-generating capacity would be affected. However, during repetitive activity, ATP must be regenerated from the aerobic and glycolytic metabolic pathways, the contribution of each depending on the demands of the task. ${ }^{65} \mathrm{~A}$ failure of the metabolic pathways to respond with increases in flux rate commensurate with increases in ATP utilization could result in a reduction in energy charge with accumulation of metabolic byproducts. ${ }^{12}$ The accumulation of selected metabolic byproducts, such as inorganic phosphate and ADP, could impair one or more of the excitation and contraction processes, resulting in an inability to translate a neural command in a desired force response. It is also important that the contribution of the aerobic pathway in ATP re-synthesis using carbohydrate as a substrate be optimized in order to increase efficiency and minimize the disruptions mediated with byproduct accumulation such as hydrogen ion. ${ }^{12}$ The apparent reduction in oxidative potential in COPD \#2 could compromise the contribution of this pathway, necessitating a greater activation of glycolysis, which may be problematic given the reduced potential also observed in this pathway in this patient.

The reduced level of both the glucose and lactate transporters observed in COPD \#2 could also impair the availability of the substrate, glucose, into the cell, ${ }^{19}$ which is needed for glycolysis, and the removal of lactate from the cell. ${ }^{20}$ Both are factors that could contribute to fatigue. ${ }^{21}$

As an added complication there is accumulating evidence to suggest that in diseases such as CHF and COPD, there are disturbances in ROS, either as a result of a more rapid production of ROS and/or a loss of antioxidant defence mechanisms. ${ }^{35}$ Repetitive contractile activity is known to increase ROS concentration and even in healthy humans to contribute to the inactivation that occurs to the cation pumps. ${ }^{45,58}$ It is possible that premature fatigue observed in COPD may also be related to ROS accumulation.

We emphasize that implications that we have provided regarding the effects of the abnormalities observed in the two patients are based on speculation only. However, they do provide a basis for beginning to predict the potential outcomes on weakness and fatigue in COPD. The assessment of many more cellular properties are possible and, indeed necessary, in order to gain a more definitive extrapolation of the mechanical defects induced. The technology and protocol for the measurement of weakness and fatigue in response to 
standardized tasks in COPD have been published and are relatively easy to administer. Much progress can be expected in the clinical application in this area in the future.

\section{Acknowledgments}

The authors gratefully acknowledge the financial assistance received from the Department of Medicine Research Award (Queen's University) and the Natural Science and Engineering Research Council (Canada) for this research. The authors report no conflicts of interest in this work.

\section{References}

1. Hamilton AL, Killian KJ, Summers E, Jones NL. Muscle strength, symptom intensity and exercise capacity in patients with cardiorespiratory disorders. Am J Respir Critical Care Med. 1995;152: 2021-2031.

2. Gosker HR, Wouters EF, van der Vusse GJ, Schols AM. Skeletal muscle dysfunction in chronic obstructive pulmonary disease and chronic heart failure: underlying mechanisms and therapy perspectives. Am J Clin Nutr. 2000;71:1033-1047.

3. Mador MJ, Bozkanat E. Skeletal muscle dysfunction in chronic obstructive pulmonary disease. Respir Res. 2001;2:216-224.

4. Troosters T, Gosselink R, Decramer M. Chronic obstructive pulmonary disease and chronic heart failure. J Cardiopul Rehab. 2004;24: 137-145.

5. Green HJ, Burnett TA, Duhamel TA, et al. Abnormal sarcoplasmic reticulum $\mathrm{Ca}^{2+}$-sequestering properties in skeletal muscle in chronic obstructive lung disease. Am J Physiol. 2008;295:C350-C357.

6. Green HJ, Burnett M, D'Arsigny C, et al. Vastus lateralis $\mathrm{Na}^{+}-\mathrm{K}^{+}$-ATPase activity, protein, and isoform distribution in chronic obstructive pulmonary disease. Muscle Nerve. 2009;40:62-68.

7. Gosker HR, van Mameren H, van Dijk PJ, et al. Skeletal muscle fibretype shifting and metabolic profile in patients with chronic obstructive pulmonary disease. Eur Respir J. 2002;19:617-625.

8. Gosker HR, Zeegers MP, Wouters EFM, Schols AM. Muscle fibre type shifting in the vastus lateralis of patients with COPD Is associated with disease severity: a systemic review and meta-analysis. Thorax. 2007:62:944-949.

9. Maltais F, Sullivan MJ, Leblanc P, et al. Altered expression of myosin heavy chain in vastus lateralis muscle in patients with COPD. Eur Respir J. 1999;13:850-854.

10. Bottinelli R, Reggiani C. Human skeletal muscle fibres: molecular and functional diversity. Prog Biophys Mol Biol. 2000;73:195-262.

11. Wouters EFM. Muscle wasting in chronic obstructive pulmonary disease. Am J Respir Crit Care Med. 2006;173:4-5.

12. Connett RJ, Honig CR, Gayeski TEJ, Brooks GA. Defining hypoxia: a systems view of $\mathrm{VO}_{2}$, glycolysis, energetics and intracellular $\mathrm{PO}_{2}$. J Appl Physiol. 1990;68:833-842.

13. Maltais F, Leblanc P, Whittom F, et al. Oxidative enzyme activities of the vastus lateralis muscle and the functional status in patients with COPD. Thorax. 2000;55:848-853.

14. Maltais F, Simard AA, Simard C, et al. Oxidative capacity of the skeletal muscle and lactic acid kinetics during exercise in normal subjects and in patients with COPD. Am J Respir Crit Care Med. 1996;153:288-293.

15. Allaire J, Maltais F, Doyon J-F, et al. Peripheral muscle endurance and the oxidative profile of the quadriceps in patients with COPD. Thorax. 2004;59:673-678.

16. Jakobsson P, Jorfeldt PL, Henriksson J. Metabolic enzyme activity in the quadriceps femoris muscle in patients with severe chronic obstructive pulmonary disease. Am J Respir Critical Care Med. 1995;151: 374-377.
17. Sauleda J, Garcia-Palmer F, Wiesner RJ, et al. Cytochrome oxidase activity and mitochondrial gene expression in skeletal muscle of patients with chronic obstructive pulmonary disease. Am J Respir Critical Care Med. 1998;157:1413-1417.

18. Green HJ, Bombardier E, D’Arsigny C, O’Donnell D, Ouyang J. Organization of metabolic pathways on skeletal muscle of patients with chronic obstructive lung disease. Am J Physiol Regul Integr Comp Physiol. 2008;295:R935-R941.

19. Holloszy JO. A forty-year memoir of research on the regulation of glucose transport into muscle. Am J Physiol. 2003;284:E453-E467.

20. Juel C, Halestrap AP. Lactate transport in skeletal muscle-role of regulation of monocarboxylate transporter. J Physiol. 1999;517: 633-642.

21. Green HJ, Burnett M, D'Arsigny C, et al. Altered metabolic and transporter characteristics in vastus lateralis in chronic obstructive pulmonary disease. J Appl Physiol. 2008;105:879-896.

22. Pette D, Staron RS. Mammalian skeletal muscle fiber type transitions. Int Rev Cytol. 1997;170:143-223.

23. Couillard A, Préfaut C. From muscle disease to myopathy to COPD: Potential contribution of oxidative stress. Eur Respir J. 2005;26: 703-709.

24. Wagner PD. Possible mechanisms underlying the development of cachexia in COPD. Eur Respir J. 2008;31:492-501.

25. Mathieu-Costello O. Comparative aspects of muscle capillary supply. Annu Rev Physiol. 1993;55:503-526.

26. Green HJ, Burnett M, D'Arsigny C, et al. Muscle fiber type characteristics in females with chronic obstructive pulmonary disease. preliminary study. J Mol Histol. 2009;40:41-51.

27. Bergström J. Muscle electrolytes in man. Scand J Clin Lab Invest. 1962;68(Suppl):1-110.

28. Staron RS, Pette D. The continuum of pure and hybrid myosin heavy chain-based fibre types in rat skeletal muscle. Histochemistry. 1993;100:149-153.

29. Ennion S, Periera JS, Sargent AJ, Young A, Goldspink G. Characterization of human skeletal muscle fibres according to the myosin heavy chain they express. J Muscle Res Cell Motil. 1995;16:35-43.

30. Parsons DB, McIntyre K, Schulz W, Stray-Gunderson J. Capillarity of elite cross-country skiiers. a lectin (Ulex Europeaus 1) marker. Scand J Med Sci Sports. 1993;3:89-98.

31. Pette D. Microphotometric measurement of initial reaction rates in quantitative enzyme histochemistry in situ. Histochem J. 1981;13: 319-327.

32. Van Der Laarse WJ, Van Nocrt P, Simonides WS, et al. Histochemistry of sarcoplasmic reticulum Ca-ATPase using dysprosiom as capturing reagent. Histocheml J. 1995;27:702-714.

33. Green HJ, Duscha BD, Kraus WE, Ketegian SJ, Sullivan MT. Association of chronic hear failure in humans with an intrinsic up regulation in sarcoplasmic reticulum $\mathrm{Ca}^{2+}$-ATPase Activity. Am J Cardiol. 2000;85:1498-1500.

34. Pette D, Dölken G. Some aspects of regulation of enzyme levels in muscle energy-supplying metabolism. Adv Enz Reg. 1975;13:355-378.

35. Henriksson JM, Chi MY, Hintz CS, et al. Chronic stimulation of mammalian muscle: changes in enzymes of six metabolic pathways. Am J Physiol. 1986;251:C614-C632.

36. Green HJ, Bombardier E, Duhamel TA, et al. Acute reductions in muscle mitochondrial and cytosolic enzyme activities during heavy intermittent exercise. J Appl Physiol. 2008;104:931-937.

37. Schacterle GR, Pollock RL. A simplified method for the quantitative assay of small amounts of protein in biologic material. Anal Biochem. 1973;51:654-655.

38. Ingebretson DC, Bakken AM, Segadal L, Farstad M. Determination of adenine nucleotides and inosine in human myocardium by ion pair reversed phase high performance liquid chromatography. J Chromatogr. 1982;242:119-126.

39. Green HJ, Duhamel T, Holloway GP, et al. Rapid upregulation of GLUT4 and MCT4 expression during sixteen hours of heavy intermittent cycle exercise. Am J Physiol. 2008;294:R594-R600. 
40. Nørgaard A, Kjeldsen $\mathrm{K}$, Hansen O. $\left(\mathrm{Na}^{+}-\mathrm{K}^{+}\right)$-ATPase activity of crude homogenates of rat skeletal muscle as estimated from their $\mathrm{K}^{+}$-dependent 3-O-methylfluorescein phosphatase activity. Biochem Biophys Acta. 1984;770:203-209.

41. Fraser SF, McKenna MJ. Measurement of $\mathrm{Na}^{+}-\mathrm{K}^{+}$-ATPase activity in human skeletal muscle. Anal Biochem. 1998;258:63-67.

42. Nørgaard A, Kjeldsen K, Clausen T. A method for the determination of the total number of ${ }^{3}$ h-ouabain binding sites in biopsies of human skeletal muscle. Scand J Clin Lab Invest. 1984;44:509-518.

43. Green HJ, Duhamel TA, Holloway GP, et al. Muscle $\mathrm{Na}^{+}-\mathrm{K}^{+}$-ATPase response during 16 hours of heavy intermittent cycle exercise. Am J Physiol. 2007;293:E523-E530.

44. Simonides WS, van Hardeveld C. An assay for sarcoplasmic reticulum $\mathrm{Ca}^{2+}$-ATPase activity in muscle homogenates. Anal Biochem. 1990;191:321-331.

45. Duhamel TA, Stewart RD, Tupling AR, Ouyang J, Green HJ. Muscle sarcoplasmic reticulum calcium regulation during consecutive days of exercise and recovery. J Appl Physiol. 2007;103:1212-1220.

46. Seidler NW, Jona I, Vegh M, Martonosi A. Cyclopiazonic acid is a specific inhibitor of the $\mathrm{Ca}^{2+}$-ATPase of sarcoplasmic reticulum. J Biol Chem. 1989;264:17816-17823.

47. MacLennan DH, Abu-Abed M, Kang C. Structure-function relationships in $\mathrm{Ca}^{2+}$-cycling proteins. J Mol Cell Cardiol. 2002;34:897-918.

48. Staron RS. Human skeletal muscle fibre types: delineation, development and distribution. Can J Appl Physiol. 1997;22:307-327.

49. McComas AJ. Skeletal muscle Form and function. Champaign, IL: Human Kinetics; 1996.

50. Pette D, Vrbova C. What does chronic electrical stimulation teach us about muscle plasticity? Muscle Nerve. 1999;22:666-677.

51. Green HJ, Sutton JR. Altitude and skeletal muscle. In: Hornbein TF, Schoene RB, editors. Lung Biology in Health and Disease. New York, NY: Marcel Dekker Inc. 2000;443-492.

52. Gosker HR, Engeler MPKJ, van Mameren H, et al. Muscle fiber type IIX atrophy is involved in the loss of fat-free mass in chronic obstructive lung disease. Am J Clin Nutr. 2002;76:113-119.

53. Whittom F, Jobin J, Simard PM, et al. Histochemical and morphological characteristics of the vastus lateralis in patients with chronic obstructive pulmonary disease. Med Sci Sports. 1998;30:1467-1474.

54. Maltais F, Leblanc P, Simard C, et al. Skeletal muscle adaptation to endurance training in patients with chronic obstructive pulmonary disease. Am J Respir Critical Care Med. 1996;154:442-447.
55. Richardson RS, Leek BT, Gavin TP, et al. Reduced mechanical efficiency in chronic obstructive pulmonary disease but normal peak $\mathrm{VO}_{2}$ with small muscle mass exercise. Am J Respir Critical Care Med. 2004;169:89-96.

56. Brooks SPJ, Storey KB. Where Is the glycolytic complex? A critical evaluation of present data from muscle tissue. FEBS Lett. 1991;276: 135-138.

57. Juel C. Training-induced changes in membrane transport proteins of human skeletal muscle. Eur J Appl Physiol. 2006;96:627-635.

58. Clausen $\mathrm{T}$. $\mathrm{Na}^{+}-\mathrm{K}^{+}$Pump regulation and skeletal muscle contractility. Physiol Rev. 2003;83:1269-1324.

59. Green HJ, Roy B, Grant S, et al. Down-regulation in muscle $\mathrm{Na}^{+}-\mathrm{K}^{+}-$ ATPase following a 21 day expedition to 6,194m. J Appl Physiol. 2000;88:634-640.

60. Gosselin N, Matecki S, Poulain M. Electrophysiologic changes during exercise testing in patients with chronic obstructive pulmonary disease. Muscle Nerve. 2003;27:170-179.

61. Berchtold MW, Brinkmeier H, Müntener M. Calcium ion in skeletal muscle: its crucial role for muscle function, plasticity and disease. Physiol Rev. 2000;80:1216-1265.

62. MacLennan DH, Rice WJ, Odermatt A, Green NM. Structurefunction relationships in the $\mathrm{Ca}^{2+}$-binding and translocation domain of SERCA 1: Physiological correlates in brody disease. Acta Physiol Scand. 2002;163(Suppl 643):55-67.

63. Morlà MM, Iglesias A, Sauleda J, et al. Reduced expression of the sarcoplasmic calcium pump SERCA2 in skeletal muscle from patients with chronic obstructive pulmonary disease and low body weight. Arch Bronconeumol. 2007;43:4-8.

64. Allen DG, Lamb AG, Westerblad H. Impaired calcium release during fatigue. J Appl Physiol. 2008;104:296-305.

65. Meyer RA, Foley JM. Cellular processes integrating the metabolic response to exercise. In: Rowell L, Shephard J, editors. Handbook of Physiology. Exercise: Regulation and Integration of Multiple Systems. New York, NY: Oxford University Press. 1996;841-869.

66. Jakobsson P, Jorfeldt PL, Brundin A. Skeletal muscle metabolites and fibre types in patients with advanced chronic obstructive pulmonary disease, with and without chronic respiratory failure. Eur Respir J. 1990;3:192-196.

67. Fiaccadori E, Del Canale S, Vitali P, et al. Skeletal muscle energetics, and acid-base equilibrium and lactate metabolism in patients with severe hypercapnia and hypoxemia. Chest. 2008;92:883-887.
International Journal of General Medicine

\section{Publish your work in this journal}

The International Journal of General Medicine is an international, peer-reviewed open-access journal that focuses on general and internal medicine, pathogenesis, epidemiology, diagnosis, monitoring and treatment protocols. The journal is characterized by the rapid reporting of reviews, original research and clinical studies across all disease areas.

\section{Dovepress}

A key focus is the elucidation of disease processes and management protocols resulting in improved outcomes for the patient.The manuscript management system is completely online and includes a very quick and fair peer-review system. Visit http://www.dovepress.com testimonials.php to read real quotes from published authors. 